\title{
CREATING EDUCATIONAL MATERIAL TO HIGH SCHOOL EDUCATION WITH COMIC BOOKS: THE VACCINA'S HISTORY.
}

Corrêa, A., Rumjanek, V., Rangel, D., de Meis, L.

Instituto de Bioquímica Médica, Universidade Federal do Rio de Janeiro, Rio de Janeiro,

Brazil.

The Comic book "The Vaccine's History" is part of a project that creates educational material intended to improve high school education, and is being developed for approximately ten years at the Bioenergetics Laboratory under Prof. Leopoldo de Meis supervision. The project's objective is joining art and science language to create more interesting and playful science education diffusion material for high school students and the general public, working as an entertainment or as an auxiliary tool for teachers in their classrooms. The book's subject is the history of immunology, from primitive man until present times, using comic book language. An extensive research was necessary in the elaboration of this present work to produce a book that is as true to facts as possible and, at the same time, develop an accessible language to general public. Collaboration of diverse scientists from the Immunology research field made possible an accurate use of academic information, translating this knowledge to students and general public about many topics of discovery and production of vaccines. All products of this project were well received by school teachers all over the country (Brazil), according to data obtained with letters and comments, and the number of requested materials of the previous works developed by this research group.

This work is supported by CAPES and FAPERJ. 